\title{
ANÁLISE DOS CONTEÚDOS DA IDENTIDADE ASSOCIADA AO LUGAR ${ }^{1}$
}

\author{
Ana Patrícia Duarte ${ }^{2}$ \\ Maria Luísa Lima
}

Resumo: Este projecto centrou-se no estudo dos conteúdos subjacentes à identidade associada ao lugar, aspecto que tem sido negligenciado pela literatura. Teve como objectivo principal proceder à identificação dos conteúdos identitários e analisar a sua relação com o grau de identificação, bem como com a dimensão da localidade alvo de identificação. Foram conduzidos dois estudos exploratórios, o primeiro de natureza qualitativa, junto de estudantes universitários, e o segundo de natureza correlacional, junto de uma amostra de residentes do Grande Porto. Os resultados apontaram para a existência de cinco dimensões de conteúdo (Instrumental, Estética, Histórico-Cultural, Resposta a Necessidades Básicas e Problemas Ambientais e Sociais), que se encontram relacionadas significativamente com as restantes variáveis em estudo. Os resultados foram discutidos à luz da literatura relevante.

Palavras-chave: identidade associada ao lugar, conteúdos identitários.

Analysis of place identity contents (abstract): This paper focus on the study of place identity contents, an issue that has been neglected by the literature. The main purpose was to identify the place identity contents and to analyse the relationships between them and the level of identification with the place, as well as with the place dimension. Two exploratory studies were conducted. The first was a qualitative study with university students, and the second a correlational one with a sample of residents living nearby Oporto. The results pointed out five content dimensions (Instrumental, Aesthetic, Historic-Cultural, Answer to Basic Needs and Environmental and Social Problems), that were significantly related to the

\footnotetext{
${ }^{1}$ A correspondência relativa a este artigo deverá ser remetida para Ana Patrícia Duarte, Departamento de Psicologia Social e das Organizações, Edifício ISCTE, Avenida das Forças Armadas, 1649-026 Lisboa, ou via Internet para patricia.duarte@iscte.pt. Este projecto foi financiado por uma bolsa de mestrado concedida pela Fundação para a Ciência e a Tecnologia e pelo Fundo Social Europeu no âmbito do III Quadro Comunitário de Apoio (SFRH/BM/4383/2001).

2 ISCTE, Lisboa.

${ }^{3}$ ISCTE, Lisboa. As autoras agradecem à Dr. ${ }^{a}$ Carla Mouro a leitura atenta e as sugestões efectuadas a uma versão anterior deste artigo.
}

PSICOLOGIA, Vol. XIX (1-2), 2005, Edições Colibri, Lisboa, pp. 193-226 
other variables under investigation. The results were discussed in the light of relevant literature.

\section{Introdução}

A importância do ambiente que nos circunda para a construção e manutenção do nosso sentido de identidade parece evidente. De facto, muitas vezes para respondemos à questão "quem sou eu?" contrapomo-la à questão "de onde sou?" ou "aonde é que pertenço?" (Cuba \& Hummon, 1993), uma manifestação de que muito do que nós somos depende de onde vivemos e das experiências que temos nesse lugar (McAndrew, 1998). Os resultados de um inquérito realizado em 2002 pelo Instituto de Ciências Sociais da Universidade de Lisboa, junto de uma amostra representativa da população portuguesa, demonstram bem a importância de sermos de um lugar e da ligação que estabelecemos com o mesmo: $41 \%$ dos inquiridos afirma sentir pertencer, em primeiro lugar, ao grupo das pessoas da localidade onde vive, contra $35 \%$ que, em primeiro lugar, sente pertencer a Portugal e $18 \%$ à região onde vive (Lima, Cabral, Vala \& Ramos, 2002, citados por Lima, 2002).

No campo da Psicologia Ambiental, Proshansky, Fabian e Kaminoff (1983) propuseram o termo identidade associada ao lugar ${ }^{4}$ (place identity) para designar a relação que se estabelece entre identidade e ambiente. A literatura sobre o lugar ${ }^{5}$ oferece, todavia, um amplo conjunto de conceitos similares e, em parte, sobreinclusivos que procuram dar conta dessa ligação, nomeadamente sentido de lugar (sense of place) (Chawla, 1992; Hummon, 1992; Jorgensen \& Stedman, 2001; Relph, 1976), ligação ou vinculação ao lugar (place attachment) (Altman \& Low, 1992; Hidalgo \& Hernandéz, 2001; Riley, 1992) e dependência ou confiança no lugar (place dependence) (Stokols \& Shumaker, 1981), apenas para referir os mais relevantes.

O conceito de identidade associada ao lugar refere-se à relação que se estabelece entre o indivíduo e um lugar específico, e ao contributo desta relação para a definição subjectiva da identidade pessoal. Na sua essência, a identidade associada ao lugar pode ser definida como uma subestrutura da identidade pessoal resultante da apropriação no autoconceito de caracte-

\footnotetext{
${ }^{4} \mathrm{O}$ termo place identity tem sido traduzido também enquanto "identidade local" ou "identidade com o lugar" (cf. Almeida \& Castro, 2002; Lima, 2002).

5 Por "lugar" entende-se um espaço ou contexto físico ao qual as pessoas ou grupos estão emocional ou culturalmente ligados e ao qual atribuíram significados através de processos pessoais, grupais ou culturais (Low \& Altman, 1992).
} 
rísticas atribuídas ao lugar. Apesar da sua importância para a teorização do constructo de identidade associada ao lugar, o modelo proposto por Proshansky e colaboradores tem sido alvo de algumas críticas, nomeadamente por equacionar a identidade associada ao lugar enquanto construção individual, negligenciando a sua componente social e cultural (Altman \& Low, 1992; Lalli, 1992). No entanto, diversos contributos posteriores têm salientado a dimensão social da identidade.

\section{Perspectivas sociais da identidade associada ao lugar}

Lalli, com base nos trabalhos de Graumann (1983, citado por Lalli, 1992), estabelece que o desenvolvimento da identidade ocorre ao longo de três fases, salientando o seu carácter eminentemente social. A primeira, que designa de processo de identificação, consiste na atribuição subjectiva de determinadas propriedades aos lugares, em resultado da experiência e da percepção de semelhanças entre objectos, indivíduos, grupos e lugares. Esta imagem socialmente partilhada tem uma determinada valorização e pode ou não ter uma correspondência com a realidade, o que permite que, por exemplo, os habitantes de uma cidade industrial considerem a mesma como "verde". Embora não implique o desenvolvimento da identidade associada ao lugar pelo indivíduo, esta primeira fase constitui uma base para a mesma. Para além deste processo, é necessário que decorram igualmente os processos de identification with e being identified with, mediante os quais o indivíduo se identifica com a cidade e constrói a sua identidade com base na consciência da pertença a um grupo definido pela partilha de um espaço, apropriando-se das características que lhe são atribuídas.

$\mathrm{Na}$ mesma linha de tentativa de compreensão dos aspectos sociais da identidade associada ao lugar, têm sido feitas adaptações quer das teorias da identidade social e autocategorização social, quer da teoria dos processos identitários para o contexto ambiental, dos quais se salientam alguns estudos. Tendo como referência teórica as teorias da identidade social e autocategorização social (Tajfel, 1978, 1981; Tajfel \& Turner, 1979; Turner, 1987), a identidade associada ao lugar pode ser conceptualizada como uma subestrutura da identidade social do indivíduo, constituída por aspectos do autoconceito baseados na sua pertença a grupos definidos geograficamente. Subjaz a esta concepção a ideia de que o ambiente pode ser visto como uma categoria social, como um produto social resultante da interacção entre as pessoas que o partilham e não apenas como um mero cenário físico onde essa interacção ocorre (Valera, 1994). Pressupõe-se, deste modo, que os princípios e estratégias utilizados em relação à identificação com o lugar são semelhantes aos utilizados no caso da identificação 
social com um grupo (e.g., Hogg \& Abrams, 1988; Hogg, 1992, citados por Bonaiuto \& Breakwell e Cano, 1996). Os estudos de Cortês e Aragonés (1991) e de Aragonés, Corraliza, Cortês e Amérigo (1992), sobre percepção do território e identidade social, e o de Bonaiuto e colaboradores (1996), sobre a influência da identidade associada ao lugar e do nacionalismo sobre a percepção de qualidade ambiental, apoiam esta posição.

Também a teoria dos processos identitários (Breakwell, 1986, 1992, 1993, 2001) tem sido utilizada como base teórica na realização de diversas investigações, que atestam a sua aplicabilidade ao estudo da identidade associada ao lugar (e.g., Devine-Wright \& Lyons, 1997; Twigger-Ross \& Uzzell, 1996), nomeadamente em contextos de mudança espacial (e.g., Speller, Lyons \& Twigger-Ross, 1996; Speller, Lyons \& Twigger-Ross, 2002), em que a identidade é muitas vezes ameaçada. Destaca-se de outras abordagens por salientar a importância dos conteúdos identitários subjacentes à identidade associada ao lugar. Segundo esta teoria, a estrutura da identidade encerra uma dimensão de conteúdo e uma dimensão avaliativa. A dimensão de conteúdo consiste nas características que definem a identidade ou, de outra forma, nas características que o indivíduo considera que o descrevem e que, no seu conjunto, o tornam uma pessoa única. Cada elemento de conteúdo tem um valor/afecto positivo ou negativo associado, definido com base nas crenças e valores sociais em interacção com valores pessoais previamente estabelecidos, que constitui, precisamente, a dimensão avaliativa. Esta encontra-se constantemente sujeita a revisões em consequência de mudanças nos sistemas de valores pessoais e sociais. Os processos identitários subjacentes à construção e manutenção da identidade são orientados por quatro princípios que definem o estado desejável para a estrutura da identidade. O princípio da distintividade refere-se ao desejo de manter uma singularidade pessoal ou, no caso da identidade associada ao lugar, à percepção dos aspectos únicos da localidade que permitem distingui-la positivamente de outras (e.g., características arquitectónicas e ambientais, serviços, estilo de vida, características dos habitantes). O princípio da continuidade constitui um segundo motivador da acção, sendo definido como o desejo de manter a continuidade ao longo do tempo e situação, ou, de outra forma, entre o(s) autoconceito(s) anterior(es) e o autoconceito actual. Speller e colaboradores $(1996 ; 2002)$ demonstraram, num conjunto de estudos efectuados durante o processo de realojamento de uma comunidade mineira, que as mudanças no contexto ambiental produzem alterações no conteúdo da identidade, afectando estes dois princípios da identidade.

O princípio da auto-estima refere-se à avaliação positiva do self ou do grupo de pertença, estando relacionado com o sentimento de valor que é atribuído ao mesmo. $\mathrm{O}$ desejo de manter uma concepção positiva do self 
tem sido visto como motivo central para a acção por muitos teóricos da identidade (e.g., Tajfel \& Turner, 1979). No que toca ao ambiente, implica a avaliação positiva do self através da pertença a um lugar e a assimilação de características atribuídas ao mesmo. Korpela (1989) demonstrou que os lugares favoritos, para além de desempenharem uma função reguladora do stress e contribuírem para a continuidade do autoconceito, favorecem o aumento dos níveis de auto-estima em crianças. Outros estudos mostram que, ao viver numa cidade histórica, as pessoas podem sentir orgulho por associação (Lalli, 1992; Uzzell, 1995, citado por Twigger-Ross \& Uzzell, 1996). No entender de Twigger-Ross e Uzzell (1996), esta ocorrência difere da realização de simples avaliações positivas do lugar (e.g., gosto de X), dado que sugere que a auto-estima da pessoa aumenta a partir das qualidades do meio (e.g., viver em $\mathrm{X}$ faz-me sentir bem comigo mesmo). Por fim, o princípio da auto-eficácia prende-se com as crenças do indivíduo relativamente à sua capacidade de gerir e responder às exigências situacionais e com o grau em que o ambiente satisfaz as suas necessidades. Se qualquer um destes princípios for comprometido, o indivíduo pode sentir a sua identidade ameaçada.

\section{O conteúdo da identidade associada ao lugar}

Não obstante os avanços realizados no estudo da identidade associada ao lugar, há um aspecto que tem sido negligenciado e cuja constatação constituiu o ponto de partida do trabalho aqui apresentado: o estudo dos conteúdos identitários. Embora a investigação empírica existente sobre identidade associada ao lugar não seja extensa, verifica-se que a maioria dos estudos utiliza uma metodologia quantitativa, preocupando-se essencialmente com a medição do grau de identidade manifestado pelos indivíduos, recorrendo a operacionalizações e instrumentos diversos (cf. Lalli, 1992) e a analisar posteriormente a sua relação com outras variáveis. Pouca atenção tem sido dada ao papel dos conteúdos identitários subjacentes à identidade associada ao lugar, que são, afinal, as dimensões da identidade que integram as propriedades e características que definem a própria identidade, conforme salientado por Breakwell (1986, 1992, 1993, 2001). Os estudos de Lima (1999), Bonaiuto, Aiello, Perugini, Bonnes e Ercolani (1999) e Gustafson (2001), embora não estando directamente direccionados para esta questão, merecem alguma atenção, na medida em que os seus resultados são sugestivos e podem ser transferidos analogicamente para este campo.

Lima (1999) demonstrou, num estudo sobre percepção de riscos associados à construção de uma incineradora, que, subjacente ao mesmo grau 
de identidade associada ao lugar, podem existir concepções diferentes da localidade, construídas a partir da valorização de diferentes características e qualidades do lugar, que determinam de forma diferente as atitudes e opções comportamentais dos residentes. Neste caso, como se adivinha em muitos outros, a simples medição do grau de identidade revela-se insuficiente para compreender as posições dos residentes face ao seu meio, sendo o conhecimento dos conteúdos identitários imprescindível. Torna-se, portanto, necessário encetar estudos que permitam identificá-los.

O trabalho de Bonaiuto e colaboradores (1999) revela igualmente que as dimensões ou conteúdos identitários determinam de forma diferente a relação que se estabelece entre o indivíduo e o seu ambiente. Com o objectivo de analisar a relevância da satisfação residencial para o desenvolvimento da ligação ao lugar, os autores aplicaram 20 escalas sobre arquitectura e planeamento (e.g., beleza estética dos edifícios, funcionalismo interno da cidade), características das relações sociais (e.g., caracteristicas dos residentes, presença de relações sociais), serviços (e.g., serviços de saúde, assistência social a idosos) e características do contexto (e.g., estilo de vida, tranquilidade) a uma amostra de habitantes da cidade de Roma. Os resultados obtidos permitiram concluir que as dimensões utilizadas na avaliação da localidade são importantes para prever a ligação ao lugar e que existe uma hierarquia no poder preditivo das mesmas, assumindo as características do contexto e as características sociais maior importância comparativamente às características arquitectónicas e de planeamento e aos serviços.

O estudo de Gustafson (2001) sobre o significado dos lugares levanta, em nosso entender, outra importante questão, que se prende com o facto de, subjacente à identidade com lugares de diferente dimensão, se poderem encontrar conteúdos identitários distintos. $\mathrm{O}$ autor constatou que os significados atribuídos espontaneamente pelos seus participantes a lugares que consideravam importantes podiam ser mapeados em torno de três pólos que designou de $E u$ (significados derivados de memórias e experiências pessoais, e.g., trajecto de vida, raízes, sentimentos), Outros (significados atribuídos com base nas características, traços e comportamentos percebidos dos habitantes, baseados, muitas vezes, em estereótipos) e Ambiente (significados relativos às características físicas, históricas, institucionais e geográficas dos lugares, e.g., localização, centralidade, clima). Mais, outros significados poderiam ser mapeados entre os pólos, como, por exemplo, as relações sociais e de vizinhança entre os pólos Eu e Outros; temas que discutem o clima social e a atmosfera no lugar entre os pólos Outros e Ambiente; significados baseados no conhecimento formal e informal do indivíduo acerca do lugar (e.g., geografia, história, famíliaridade) em torno dos pólos Eu e Ambiente; e, finalmente, alguns temas entre 
todos os pólos (e.g., cidadania, tradições, participação social em instituições locais).

\section{A importância da dimensão do lugar}

No mesmo estudo, Gustafson verificou ainda que os significados atribuídos aos lugares divergiam com alguma coerência conforme a dimensão dos mesmos. Basicamente, aos lugares de menor dimensão (e.g., residências, bairros, vilas ou pequenas cidades) eram atribuídos, muitas vezes significados situados nos pólos Eu, Eu e Outros e Eu e Ambiente, que implicam uma referência directa à pessoa; aos lugares de maior dimensão (e.g., cidades grandes, regiões, continente) eram atribuídos com maior frequência significados situados nos pólos Outros e Ambiente, sem referência directa ao indivíduo.

Apesar de Altman e Low (1992) terem afirmado, há sensivelmente uma década, que os lugares a que as pessoas se ligam e com que se identificam variam em escala, especificidade e tangibilidade, esta questão permanece pouco explorada em termos empíricos. A maioria dos estudos efectuados sobre identidade associada ao lugar foca, primordialmente, o significado que determinados contextos físicos têm para o desenvolvimento e manutenção da identidade do indivíduo (e.g., casa, bairro), sendo poucos os que analisam a relevância de diferentes espaços físicos em simultâneo. O estudo de Cuba e Hummon (1993) constitui uma das excepções nesta matéria, tendo os autores constatado que as pessoas se identificam, embora em graus diferentes, com vários espaços em simultâneo (residência, cidade e região) e que a identificação com cada um dos lugares é determinada por diferentes conteúdos afiliativos, resultantes da interpretação do lugar e das experiências tidas no mesmo.

Mais recentemente, Hidalgo e Hernandéz (2001) estudaram a questão da ligação a diferentes espaços (residência, bairro e cidade), introduzindo duas dimensões de ligação ao lugar: ligação física (relacionada com a mudança de ambiente físico e a manutenção do ambiente social, i.e., como se sentiria o indivíduo se mudasse de residência acompanhado pelas pessoas que o rodeiam) e ligação social (relacionada com a mudança de ambiente social e a manutenção do ambiente físico, i.e., como se sentiria o indivíduo se as pessoas que o rodeiam mudassem de residência, permanecendo ele no mesmo lugar). Os resultados relativos à identificação com vários locais vão no sentido dos de Cuba e Hummon (1993). Relativamente às dimensões da ligação ao lugar, mostram que a ligação física é mais forte quando o foco de ligação é a cidade, enquanto que a ligação social é mais forte quando o foco de ligação é a residência. Consideramos que este resul- 
tado sugere que a identificação com um lugar de menor dimensão poderá resultar da avaliação dos seus aspectos e características sociais, enquanto que a identificação com um lugar de maior dimensão poderá ter subjacente uma avaliação mais genérica, orientada para as características físicas do lugar, nomeadamente as apontadas por Bonaiuto e colaboradores (1999).

\section{Objectivos gerais}

Considerando a análise dos conteúdos e significados que subjazem à identificação dos indivíduos com o seu ambiente vital para a compreensão da relação que entre estes se estabelece, definiram-se os seguintes objectivos gerais:

1. Identificar os conteúdos identitários subjacentes à identidade associada ao lugar;

2. Analisar a relação entre o grau de identificação, a dimensão da localidade e os conteúdos identitários.

Seguidamente, apresentam-se os dois estudos exploratórios realizados com vista ao alcance dos objectivos propostos.

\section{Estudo 1}

\section{Objectivo}

O presente estudo assumiu uma natureza qualitativa e teve como objectivo principal identificar os conteúdos identitários subjacentes à identidade associada ao lugar.

\section{Método}

\section{Participantes}

Pretendeu-se neste estudo obter a colaboração de indivíduos provenientes de localidades portuguesas de diferente dimensão, mais concretamente de cidades, vilas e aldeias. Tendo em conta a diversidade de proveniência dos estudantes universitários, optou-se por recorrer à sua colaboração. Assim, participaram no presente estudo 103 estudantes universitários, maioritariamente do sexo feminino $(84,0 \%)$, com idades compreendidas entre os 18 e os 36 anos $(M=21,5$; $\mathrm{DP}=3,99)$. A maioria dos mesmos $(54,4 \%)$ indicou uma cidade como sendo a sua terra, $35,9 \%$ uma vila e $9,7 \%$ uma aldeia. A maioria dos participantes reside actualmente na locali- 
dade por si indicada $(63,4 \%)$, embora não seja natural da mesma $(55,7 \%)$. De referir que, no conjunto, as respostas obtidas têm por base a referência a localidades distribuídas geograficamente por todo o país, incluindo os arquipélagos da Madeira e dos Açores.

De forma a analisar a relação entre a dimensão da localidade e as restantes variáveis em estudo, agruparam-se os participantes por dois tipos de localidade, que se designaram de cidades $(n=56)$ e vilas/aldeias $(n=47)$.

\section{Instrumento e Procedimento}

A recolha de dados foi realizada mediante a aplicação de um questionário construído para o efeito, preenchido individualmente pelos participantes em sala de aula. Este instrumento era composto pelas seguintes medidas:

\section{Identificação da "terra" do participante.}

Solicitou-se a cada participante que, independentemente da localidade em que actualmente residisse, indicasse a localidade que considerava ser a sua terra.

\section{Identidade associada ao lugar.}

A identidade associada ao lugar foi avaliada através de dois tipos de medida, nomeadamente uma escala de identidade que permitiu quantificar o grau de identificação com o lugar e um conjunto de questões de resposta aberta que permitiu aceder aos conteúdos simbólicos ou às dimensões de avaliação subjacentes a essa identificação.

A escala de identidade associada ao lugar é composta pelos itens "sinto que pertenço a esse lugar", "sinto-me orgulhoso por pertencer a esse lugar" e "gosto muito desse lugar" e apresentou uma boa consistência interna $(\alpha=0,87)$. A resposta aos itens foi dada numa escala de cinco pontos, que varia entre 1 ("discordo totalmente") e 5 ("concordo totalmente"), sendo usado nas análises posteriores o índice composto pela média dos 3 itens.

Para aceder aos conteúdos simbólicos subjacentes a essa identificação colocaram-se oito questões abertas. Destas, uma foi adaptada de Krupat $(1985 / 1999)$ e permite aceder à representação geral da localidade: "Imagine que se encontra a conversar com alguém que ainda não conhece a sua terra. Como descreveria a sua terra a essa pessoa? Indique o maior número de características possível". As restantes foram elaboradas tendo por base os princípios da identidade propostos por Breakwell (1986, 1992, 1993, 2001), e.g.: "Considera que a sua terra possui características únicas que a tornam diferente das outras localidades? Se sim, quais?", "Considera que os mesmos [habitantes] possuem características únicas que os tornam diferentes dos habitantes de outras localidades? Se sim, quais?", "Indique, 
por favor, quais os aspectos da sua terra de que mais gosta."; "E quais os que menos gosta?", "que condições gostaria que fossem ainda criadas?".

Caracterização sociodemográfica.

Recolheu-se informação sobre o participante (sexo, idade, habilitações académicas, naturalidade, local de residência actual, anos de residência no mesmo) e sobre a localidade indicada (concelho a que pertence, dimensão - aldeia, vila ou cidade).

\section{Análise de conteúdo}

As respostas obtidas às questões abertas foram submetidas a uma análise de conteúdo, com o objectivo de identificar os conteúdos subjacentes à identidade associada ao lugar, ou, de outra forma, que dimensões, motivos, elementos ou características estão salientes para os indivíduos na avaliação da sua terra. O sistema de categorias utilizado foi totalmente construído a posteriori, através da leitura e levantamento dos conteúdos contidos no corpus, definindo-se como unidade de registo o tema. É constituído por 73 categorias, agrupadas em oito dimensões:

(a) Dimensão Social, que agrega oito categorias relacionadas com aspectos sociais da relação do indivíduo com o meio, entre as quais a existência de Redes Sociais, Raízes e Espírito de Comunidade;

(b) Caracterização dos Habitantes, que agrega nove categorias utilizadas para a caracterização dos habitantes, das quais quatro são positivas (e.g., Mentalidade Aberta, Simpatia), quatro negativas (e.g., Mentalidade Fechada, Impessoalidade) e uma neutra (Pronúncia Específica);

(c) Caracterização do Património Histórico e Cultural, que agrega cinco categorias que permitem realizar a caracterização histórica e cultural da localidade, entre as quais os Monumentos, as Tradições e a Gastronomia;

(d) Caracterização do Património Natural, que agrega sete categorias referentes ao património natural da localidade, entre as quais a Beleza da Paisagem, a Proximidade com a Natureza, os Espaços Verdes Suficientes e Insuficientes;

(e) Caracterização do Ambiente Físico e Social, que agrega oito categorias que permitem caracterizar o ambiente físico e social da localidade, entre as quais a Avaliação Positiva da Localidade, a Qualidade Ambiental, a Poluição, o Bulício e a Tranquilidade;

(f) Caracterização Económica, que agrega oito categorias relacionadas com a caracterização económica da localidade, nomeadamente o Desenvolvimento da Localidade, a Estagnação da Localidade, Maiores Oportunidades de Emprego, Menor Custo de Vida; 
(g) Caracterização Sociodemográfica, que engloba nove categorias que permitem caracterizar sociodemograficamente a localidade, designadamente: Pequena Dimensão, População Jovem, Dormitório, Segurança, Diversidade/Heterogeneidade de Pessoas;

(h) Caracterização das Infra-Estruturas e Serviços Locais, que agrega 19 categorias que permitem caracterizar as infra-estruturas e serviços locais, a vários níveis, incluindo a saúde, o ensino, o trânsito, os transportes públicos, as infra-estruturas rodoviárias e desportivas, entre outras. O leitor interessado encontrará uma descrição detalhada do sistema de categorias utilizado em Baltazar (2002).

De forma a garantir a exaustividade e exclusividade das categorias e, consequentemente, a sua validade, procedeu-se ao cálculo do acordo interjuízes. Obteve-se um $\mathrm{K}$ de Cohen de 0,90 para o conjunto das oito dimensões, valor considerado excelente (Robson, 1993), mas que, dada a natureza relativamente objectiva da categorização, não se considera surpreendente. Após a análise de conteúdo ao corpus, registou-se em base de dados a utilização de cada uma das categorias por participante, criando-se uma matriz de presenças e ausências.

\section{Resultados}

\section{Grau de identidade associada ao lugar}

Os participantes reportam globalmente uma forte identidade associada ao lugar $(M=4,18 ; D P=0,76)$, não se verificando diferenças significativas em função da dimensão da localidade $(F(1,102)=0,03$, n.s. $)$.

Com vista a analisar a relação entre o grau de identidade associado ao lugar e as restantes variáveis em estudo, procedeu-se à constituição de dois grupos, com base na média da amostra, que se designaram de baixa $(42,7 \%)$ e alta identidade associada ao lugar $(57,3 \%)$.

\section{Conteúdos Identitários}

A análise da frequência das categorias permitiu verificar grandes discrepâncias no número de ocorrências das mesmas. As categorias "Raízes" (61,2\%), "Tranquilidade" (54,2\%), "Redes Sociais" (52,2\%) e “Avaliação Positiva da Localidade" $(45,6 \%)$ assumem um papel central na descrição das localidades, sendo referidas por mais de $45,0 \%$ dos participantes como factores de ligação à terra. Outras categorias salientes são a "Centralidade", "Espaços Verdes Suficientes", "Praia e Mar", "Suficientes Ofertas Culturais e de Lazer", "Insuficientes Ofertas Culturais e de Lazer", "Simpatia" e "Qualidade Ambiental", cujas frequências oscilam entre os 30\% e 
$20 \%$. O Quadro 1 apresenta as frequências das categorias com mais de 10 observações.

Quadro 1: Categorias com mais de 10 observações: frequências em função da dimensão da localidade.

\begin{tabular}{|c|c|c|c|}
\hline & Cidade & Vila ou Aldeia & Total \\
\hline Categoria & $\mathbf{N}(\%)$ & $\mathbf{N}(\%)$ & $\mathbf{N}(\%)$ \\
\hline Raízes & $34(60,7)$ & $29(66,7)$ & $63(61,2)$ \\
\hline Tranquilidade* & $25(45,0)$ & $31(66,0)$ & $56(54,4)$ \\
\hline Redes Sociais & $26(46,4)$ & $28(59,6)$ & $54(52,4)$ \\
\hline Avaliação Positiva da Localidade & $22(39,3)$ & $25(53,2)$ & $47(45,6)$ \\
\hline Centralidade & $17(30,4)$ & $14(29,8)$ & $31(30,1)$ \\
\hline Espaços Verdes Suficientes* & $23(41,1)$ & $8(17,0)$ & $31(30,1)$ \\
\hline Praia e Mar & $14(25,0)$ & $15(31,9)$ & $29(28,2)$ \\
\hline Suficientes Ofertas Culturais e de Lazer* & $19(33,9)$ & $8(17,0)$ & $27(26,2)$ \\
\hline Insuficientes Ofertas Culturais e de Lazer & $13(23,2)$ & $11(23,4)$ & $24(23,3)$ \\
\hline Simpatia & $12(21,4)$ & $12(25,5)$ & $24(23,3)$ \\
\hline Qualidade Ambiental & $9(16,1)$ & $12(25,5)$ & $21(20,4)$ \\
\hline Espírito de Comunidade* & $4(7,1)$ & $14(29,8)$ & $18(17,5)$ \\
\hline Insegurança & $11(19,6)$ & $7(14,9)$ & $18(17,5)$ \\
\hline Trânsito Elevado & $13(23,2)$ & $5(10,6)$ & $18(17,5)$ \\
\hline Menores Oportunidades de Emprego & $10(17,9)$ & $7(14,9)$ & $17(16,5)$ \\
\hline Beleza da Paisagem & $10(17,9)$ & $7(14,9)$ & $16(15,5)$ \\
\hline Proximidade com a Natureza ${ }^{* *}$ & $2(3,6)$ & $14(29,8)$ & $16(15,5)$ \\
\hline Segurança & $9(16,1)$ & $7(14,9)$ & $16(15,5)$ \\
\hline Tradições & $10(17,9)$ & $6(12,8)$ & $16(15,5)$ \\
\hline Acessibilidade de Serviços & $8(14,3)$ & $7(14,9)$ & $15(14,6)$ \\
\hline Espaços Verdes Insuficientes & $5(8,9)$ & $9(19,1)$ & $14(13,6)$ \\
\hline Monumentos & $8(14,3)$ & $6(12,8)$ & $14(13,6)$ \\
\hline Simplicidade & $7(12,5)$ & $7(14,9)$ & $14(13,6)$ \\
\hline Passado Histórico & $6(10,7)$ & $6(12,8)$ & $12(11,7)$ \\
\hline
\end{tabular}


(continuação)

\begin{tabular}{lccc}
\hline & Cidade & Vila ou Aldeia & Total \\
\cline { 2 - 3 } Categoria & $\mathbf{N ~ ( \% )}$ & $\mathbf{N}(\mathbf{\%})$ & $\mathbf{N}(\mathbf{\%})$ \\
\hline \multicolumn{1}{c}{ Bulício* $^{*}$} & $\mathbf{9 ( 1 6 , 1 )}$ & $\mathbf{2 ( 4 , 3 )}$ & $\mathbf{1 1}(\mathbf{1 0 , 7 )}$ \\
Falta de Privacidade & $6(10,7)$ & $5(10,6)$ & $11(10,7)$ \\
Infra-Estruturas Rodoviárias Insuficientes & $9(16,1)$ & $6(12,8)$ & $11(10,7)$ \\
Património Arquitectónico & $8(14,3)$ & $3(6,4)$ & $11(10,7)$ \\
Clima & $6(10,7)$ & $4(8,5)$ & $10(9,7)$ \\
Infra-Estruturas de Ensino Insuficientes & $7(12,5)$ & $4(8,5)$ & $10(9,7)$ \\
Poluição & $8(14,3)$ & $2(4,3)$ & $10(9,7)$ \\
\hline
\end{tabular}

Nota: As categorias onde se verificam diferenças significativas entre localidades encontram-se assinaladas a negrito: $* p<0,05, * * p<0,000$

Deste conjunto de categorias, seis encontram-se associadas de forma significativamente diferente a localidades de diferente dimensão, conforme assinalado no Quadro 1 a negrito. São elas as categorias "Tranquilidade" $\left(\chi^{2}(1)=4,68, p=0,031\right)$, Proximidade com a Natureza $\left(\chi^{2}(1)=13,39\right.$, $p=0,000)$ e Espírito de Comunidade $\left(\chi^{2}(1)=9,09, p=0,003\right)$, a favor das vilas/aldeias; e "Bulício" $\left(\chi^{2}(1)=3,44, p=0,05\right)$, "Suficientes Espaços Verdes" $\left(\chi^{2}(1)=7,03, p=0,008\right)$ e "Suficientes Ofertas Culturais e de Lazer" $\left(\chi^{2}(1)=3,78, p=0,05\right)$ a favor das cidades. Neste sentido, verifica-se que as cidades, comparativamente com as vilas/aldeias, são vistas como lugares com um ritmo de vida mais agitado e menos tranquilo, onde o espírito de comunidade e a proximidade com a natureza são menores, mas que oferecem aos seus habitantes melhores ofertas culturais e de lazer e mais espaços verdes construídos, compensando-os, de certa forma, pela menor proximidade com a natureza.

Os resultados dos testes do Qui-quadrado efectuados entre os níveis de identidade e as diversas categorias apuradas apresentam valores significativos apenas nas categorias "Qualidade Ambiental" $\left(\chi^{2}(1)=8,72\right.$, $p=0,003)$ e "Espírito de Comunidade" $\left(\chi^{2}(1)=3,75, p=0,05\right)$, mostrando que os indivíduos mais identificados com o lugar utilizam mais frequentemente estas categorias na descrição das suas terras, o que mostra que a percepção de qualidade ambiental e de um espírito de comunidade forte está mais saliente para os participantes que se identificam fortemente com as suas terras do que para os que se identificam menos com as mesmas. 
Quadro 2: Medidas de discriminação e coordenadas das categorias nas dimensões da Homals

\begin{tabular}{|c|c|c|c|c|}
\hline \multirow[b]{2}{*}{ Categoria } & \multicolumn{2}{|c|}{$\begin{array}{c}\text { Medidas de } \\
\text { discriminação }\end{array}$} & \multicolumn{2}{|c|}{$\begin{array}{l}\text { Coordenadas nas } \\
\text { dimensões }\end{array}$} \\
\hline & $\begin{array}{c}\text { Dimensão } \\
1 \\
\end{array}$ & $\begin{array}{c}\text { Dimensão } \\
2 \\
\end{array}$ & $\begin{array}{c}\text { Dimensão } \\
1 \\
\end{array}$ & $\begin{array}{c}\text { Dimensão } \\
2 \\
\end{array}$ \\
\hline Qualidade ambiental &, 051 &, 057 & $-0,45$ & $-0,47$ \\
\hline Poluição & ,407 & ,003 & 1,95 & 0,17 \\
\hline Clima &, 097 & ,049 & $-0,95$ & $-0,68$ \\
\hline Suficientes ofertas culturais e de lazer & ,289 &, 050 & 0,90 & $-0,38$ \\
\hline Insuficientes ofertas culturais e de lazer &, 064 & 033 & $-0,46$ & 0,33 \\
\hline Bulício & ,303 &, 053 & 1,59 & 0,67 \\
\hline Tranquilidade & ,463 & ,009 & $-0,62$ & 0,09 \\
\hline Avaliação positiva da localidade & 000 &, 050 & $-0,02$ & $-0,24$ \\
\hline Segurança & ,098 &, 097 & $-0,73$ & 0,73 \\
\hline Insegurança &, 115 &, 118 & 0,74 & 0,75 \\
\hline Menores oportunidades de emprego & 029 &, 034 & $-0,39$ & $-0,41$ \\
\hline Redes sociais & 078 & ,003 & $-0,27$ & $-0,05$ \\
\hline Falta de privacidade &, 136 &, 011 & $-1,07$ & $-0,30$ \\
\hline Raízes &, 025 &, 010 & $-0,13$ & 0,08 \\
\hline Espírito de comunidade & ,174 &, 005 & $-0,91$ & 0,16 \\
\hline Simpatia & 078 & 079 & $-0,51$ & $-0,51$ \\
\hline Simplicidade & 088 & 030 & $-0,75$ & $-0,44$ \\
\hline Espaços verdes insuficientes &, 001 &, 144 & $-0,06$ & 0,96 \\
\hline Centralidade &, 000 & ,329 & 0,03 & 0,87 \\
\hline Acessibilidade de serviços & 065 & ,485 & 0,62 & 1,69 \\
\hline $\begin{array}{l}\text { Infra-estruturas rodoviárias } \\
\text { insuficientes }\end{array}$ & ,008 & ,133 & $-0,22$ & 0,88 \\
\hline Trânsito elevado &, 254 &, 024 & 1,09 & 0,33 \\
\hline Infra-estruturas de ensino insuficientes & ,009 & ,076 & 0,28 & 0,80 \\
\hline Monumentos & ,236 & ,187 & 1,22 & $-1,09$ \\
\hline Património arquitectónico &, 103 &, 070 & 0,93 & $-0,77$ \\
\hline Passado histórico &, 133 & ,225 & 1,01 & $-1,31$ \\
\hline Tradições & ,008 & 053 & $-0,20$ & $-0,54$ \\
\hline Beleza da paisagem &, 056 & ,195 & 0,55 & $-1,03$ \\
\hline Proximidade com a natureza &, 056 & ,102 & $-0,55$ & $-0,74$ \\
\hline Praia e mar &, 021 &, 019 & $-0,23$ & 0,22 \\
\hline Espaços verdes suficientes &, 000 & 001 & 0,03 & 0,05 \\
\hline
\end{tabular}


A realização de uma Análise de Homogeneidade com as categorias que constam da Quadro 1 permitiu perceber como estas se associam entre si. Os resultados da Homals são resumidos em duas dimensões, sendo que a primeira é mais explicativa do que a segunda (valores próprios de $0,11 \mathrm{e}$ 0,09 respectivamente), e que convergiu numa solução ao fim de 12 iterações. O Quadro 2 apresenta as medidas de discriminação e as coordenadas das categorias nas dimensões.

As medidas de discriminação mostram que as categorias que mais contribuem para a definição do primeiro eixo são as categorias "Tranquilidade", "Poluição", "Bulício", "Suficientes Ofertas Culturais e de Lazer", "Trânsito Elevado" e "Monumentos". Através das coordenadas das categorias podemos verificar que a primeira dimensão opõe uma representação da localidade assente na "Tranquilidade" a uma representação associada ao "Bulício" e à "Poluição ambiental".

O segundo eixo é definido pelas categorias "Acessibilidade de Serviços", "Centralidade" e "Passado Histórico" e opõe uma visão mais prática/instrumental da localidade, assente essencialmente na caracterização das infra-estruturas e serviços locais indispensáveis à vida quotidiana, a uma visão essencialmente estética, apoiada na beleza da paisagem e na riqueza do seu passado histórico.

A observação mais cuidada dos quadrantes resultantes do cruzamento das duas dimensões identificadas revela a existência de quatro formas distintas de conceber as localidades (Figura 1). A primeira, resultante da intersecção dos pólos "Tranquilidade" e "Visão Instrumental", integra as categorias "Espírito de Comunidade", "Praia e Mar", "Segurança", "Ofertas Culturais e de Lazer Insuficientes", "Infra-estruturas Rodoviárias Insuficientes (estradas e estacionamentos)" e "Espaços verdes Insuficientes". A segunda, resultante da intersecção dos pólos "Tranquilidade" e "Visão Estética", integra as categorias "Avaliação Positiva da Localidade", "Simpatia", "Tradições", "Simplicidade", "Redes Sociais", "Clima", "Proximidade com a natureza", "Qualidade Ambiental", "Falta de Privacidade", uma combinação que aponta para a localidade como, no fundo, um meio onde as pessoas e as relações que se estabelecem entre estas assumem um papel central, embora alguns excessos possam originar a falta de privacidade. A terceira resulta da intersecção dos pólos "Bulício" e "Visão Instrumental", reunindo as categorias "Acessibilidade de Serviços", "Centralidade", "Insuficientes Infra-estruturas de ensino", "Insegurança", "Bulício", "Trânsito" e "Poluição". Por último, a quarta resulta da intersecção dos pólos "Bulício" e "Visão Estética" e constitui essencialmente uma visão positiva da localidade, assente nas ofertas culturais e de lazer suficientes, na riqueza de monumentos e do património arquitectónico local e na beleza da paisagem. 
Figura 1: Representação gráfica das categorias nas dimensões da HOMALS

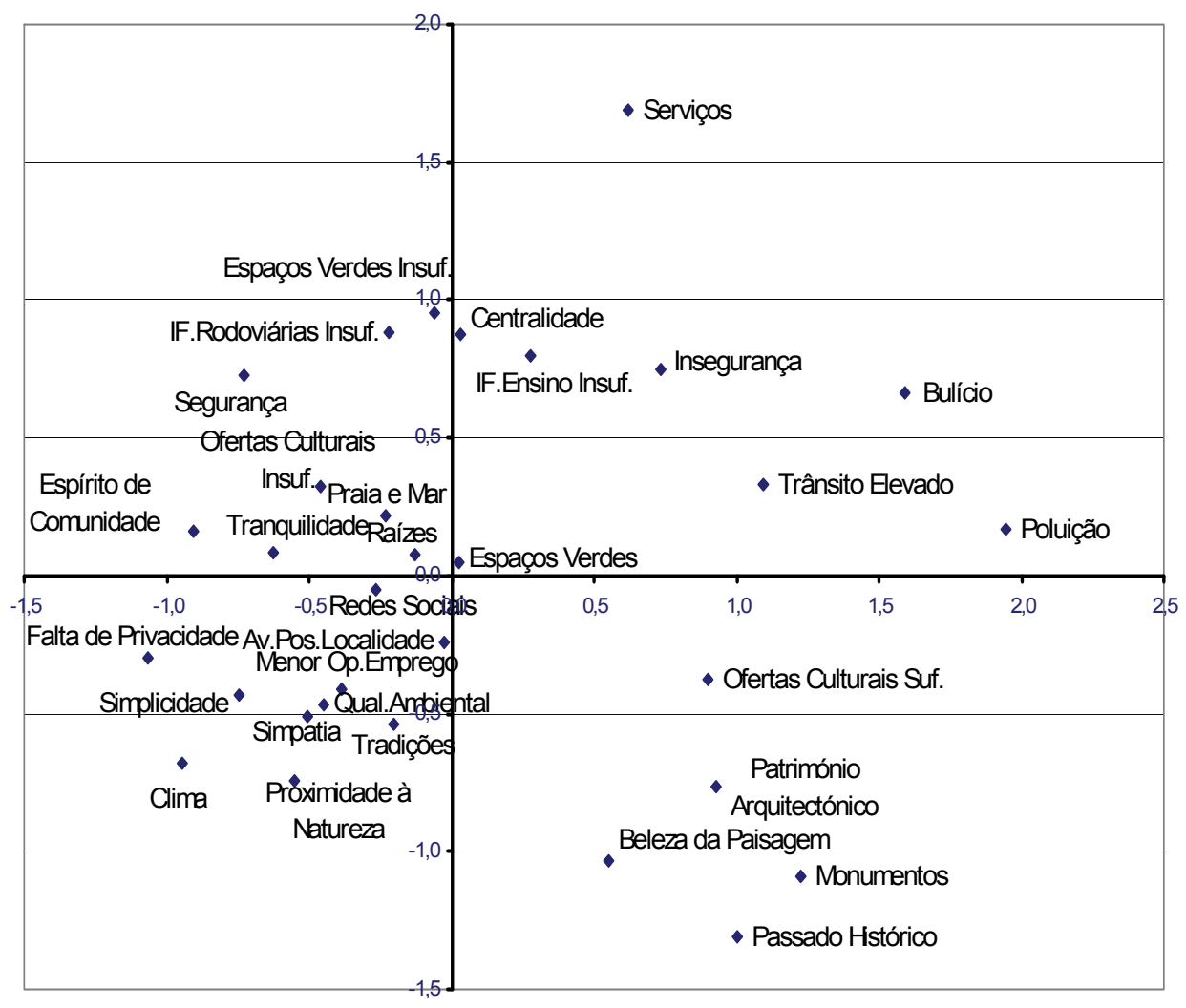

Legenda: IF= Infra-Estrutura; Suf. = Suficiente; Insuf. = Insuficiente; Av.Pos. = Avaliação Positiva; Qual. = Qualidade; OP. = Oportunidade.

A projecção das pertenças dos indivíduos no espaço definido pelos dois eixos permitiu associar as suas características (grau de identidade, dimensão da sua terra, residência actual e sexo) às dimensões encontradas na Homals. A Figura 2 apresenta as coordenadas das variáveis que apresentam diferenças significativas. Assim, a primeira dimensão (Tranquilidade/Bulício) diferencia significativamente os indivíduos com alta e baixa identidade associada ao lugar $(F(1,102)=5,25, p=0,02)$, os indivíduos que se referem a vilas/aldeias dos que se referem a cidades $(F(2,102)=6,73, p=0,002)$ e, ainda, os que actualmente não residem na sua terra dos que presentemente o fazem $(F(1,100)=13,86, p=0,000)$. A 
segunda dimensão (Instrumental/Estética) apenas diferencia significativamente os indivíduos que actualmente não residem na sua terra dos que presentemente o fazem $(F(1,102)=11,92, p=0,001)$, não se verificando diferenças entre indivíduos que se referem a cidades, vilas e aldeias $(F(2,102)=6,73$, n.s. $)$ nem entre indivíduos com alta e baixa identidade associada ao lugar $(F(1,102)=2,24$, n.s.). Não foram encontradas diferenças significativas no que se refere ao sexo dos participantes em nenhuma das dimensões $(F(1,99)=2,27$, n.s. e $F(1,99)=0,92$, n.s., respectivamente).

Em suma, são os indivíduos que (a) vivem presentemente nas suas terras, (b) se referem a cidades, e (c) apresentam uma menor identidade associada ao lugar que consideram que a sua terra apresenta mais características associadas ao bulício e à poluição, por oposição aos participantes que (d) não vivem presentemente nas suas terras, (e) referem-se a aldeias, e (f) apresentam uma maior identidade associada ao lugar, que consideram que a sua terra é mais tranquila. Para além disso, são também os indivíduos que presentemente vivem nas suas terras que estão mais atentos às questões práticas e funcionais da localidade, relacionadas com a vida quotidiana, por oposição aos participantes que presentemente não vivem nas suas terras, que possuem uma representação essencialmente estética da localidade, assente nomeadamente na beleza da paisagem e na riqueza do património histórico, consequência provável do distanciamento da realidade quotidiana local e da elaboração de uma visão romanceada da localidade.

Figura 2: Representação gráfica das características dos participantes nas dimensões da HOMALS

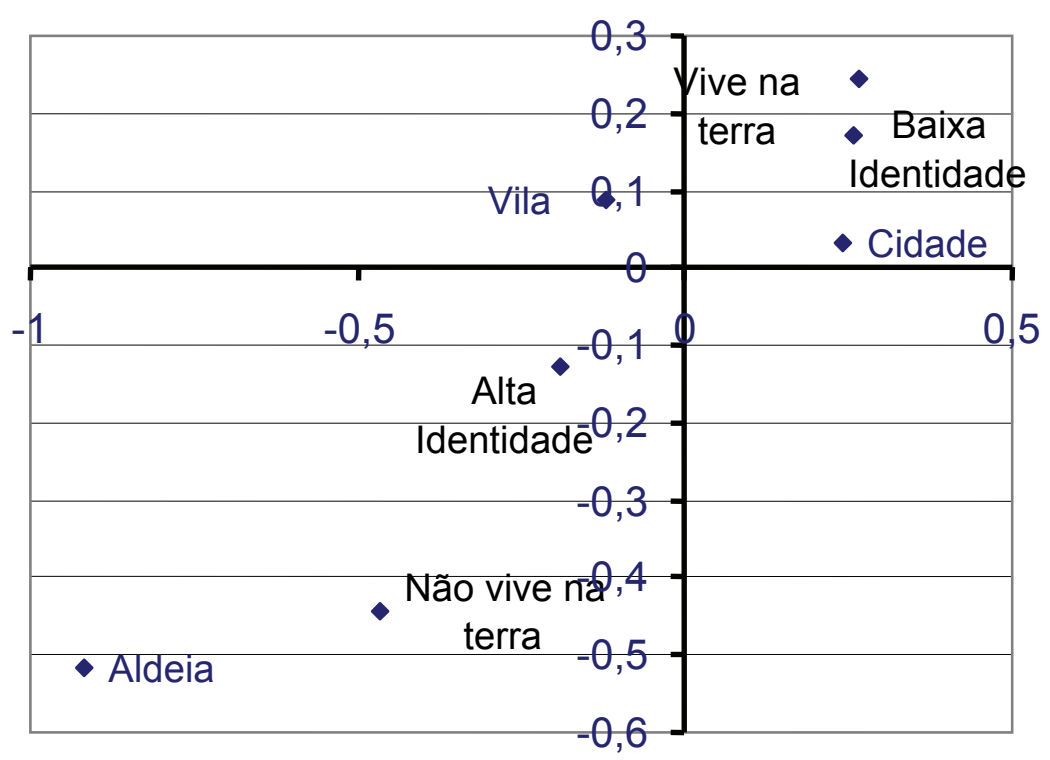


Analisando conjuntamente as Figuras 1 e 2, e tendo em conta a dimensão da localidade, observa-se que as aldeias estão posicionadas no Quadrante 2 (Tranquilidade/Visão Estética), as vilas no Quadrante 1 (Tranquilidade/Visão Instrumental) e as cidades no Quadrante 3 (Bulício/Visão Instrumental), o que corresponde amplamente à representação geralmente partilhada pelo senso comum acerca destes locais. As aldeias surgem, então, como os locais onde a tranquilidade, a proximidade com natureza e os aspectos sociais da vida em comunidade assumem maior destaque, face à menor oferta de serviços e de infra-estruturas locais. As cidades, por seu turno, são representadas como um meio agitado e poluído em que a maior oferta de serviços e de infra-estruturas coexiste com problemas ambientais e sociais. As vilas surgem, de certa forma, como ponte entre estes dois tipos de localidade, apresentando a tranquilidade, o espírito de comunidade e a segurança como principais características positivas, embora estejam salientes para os seus habitantes as limitações existentes a nível de infra-estruturas e serviços locais.

\section{Discussão}

O presente estudo assumiu uma natureza qualitativa exploratória e teve como principal objectivo identificar os conteúdos identitários subjacentes à identidade associada ao lugar. A análise dos mesmos teve em conta a dimensão da localidade e o grau de identidade reportado pelos participantes.

Os resultados obtidos demonstram que os indivíduos atendem a diversos aspectos do seu ambiente urbano para o caracterizar, nomeadamente a características da vida social, dos habitantes, do património histórico-cultural, do património natural, do ambiente físico e social e, ainda, a aspectos económicos, sociodemográficos e outros relacionados com as infra-estruturas e serviços locais. A existência de similaridades entre os conteúdos identificados no presente estudo com os de Bonaiuto e colaboradores (1999) e os de Gustafson (2001) apontam para a existência de constância nas características e dimensões com base nas quais as pessoas avaliam e edificam a sua identidade associada ao lugar.

Os resultados obtidos neste estudo revelam, ainda, que a multiplicidade de categorias identificadas através da análise de conteúdo se associam com base em duas dimensões, que se designaram de Tranquilidade/Bulício e Instrumental/Estética. A associação destas dimensões à própria dimensão das localidades revela que são as pessoas que se identificam com cidades que se encontram mais atentas às questões práticas e funcionais, utilizando mais elementos deste nível para caracterizar as suas terras do que aquelas 
que se identificam com vilas e aldeias. No seu conjunto, os participantes possuem representações diferentes de cidades, vilas e aldeias assentes em categorias distintas, representações essas que correspondem em larga medida àquelas que são geralmente partilhadas pelo senso comum. Assim, as aldeias são representadas como lugares tranquilos, próximos da natureza, nos quais os aspectos sociais e comunitários assumem maior destaque. As cidades, pelo contrário, são representadas como meios agitados e poluídos, em que a maior oferta de serviços e infra-estruturas locais coexiste com problemas sociais e ambientais. As vilas surgem como lugares intermédios, como uma ponte entre os dois mundos, apresentando a tranquilidade, o espírito de comunidade e a segurança como principais atributos. $\mathrm{O}$ facto de as representações dos três tipos de localidades englobarem tanto aspectos positivos como negativos vai ao encontro do já constatado por Fried (1982, 2000). Segundo o autor, a maioria das pessoas tem uma visão positiva dos locais em que vive, porque se habitua ou se torna insensível às fontes de insatisfação com o continuar da vivência no lugar. Saliente-se que não é uma questão de ficar "cego à realidade" (a atribuição de características negativas aos lugares assim o comprova), mas de minimizar os aspectos negativos e valorizar os positivos, de forma a apreciar favoravelmente o lugar de residência.

Outro aspecto interessante dos resultados obtidos neste primeiro estudo resulta da associação das características dos participantes às dimensões que estruturam o conjunto global das categorias identificadas. Os resultados sugerem que o facto de as pessoas viverem ou não na localidade que consideram ser a sua terra se traduz numa avaliação qualitativamente diferente da mesma. As que vivem na sua terra estão mais atentas a aspectos específicos da sua experiência directa com o meio (e.g., poluição, serviços existentes), enquanto que as que não residem nas suas terras as avaliam com base em aspectos ou atributos gerais do lugar, recorrendo às memórias que possuem do mesmo (e.g., beleza, património histórico). Futuramente, será importante desenvolver uma investigação centrada neste domínio a fim de apurar concretamente qual a influência desta variável sobre a avaliação dos lugares e sobre o desenvolvimento da identidade associada aos mesmos.

\section{Estudo 2}

\section{Objectivos}

O estudo 2 visou a construção de uma escala de conteúdos identitários com base nas categorias identificadas no estudo 1 cuja aplicação a uma 
amostra de participantes permitisse analisar a estrutura factorial dos conteúdos identitários. Pretendeu-se, desta forma, identificar os factores/dimensões de conteúdo mais explicativas da variabilidade de respostas existente. A análise das mesmas realizou-se tendo por base, uma vez mais, o grau de identificação com o lugar e da dimensão da localidade.

\section{Método}

\section{Participantes}

Este estudo foi realizado no âmbito da monitorização do impacte psicossocial da construção e funcionamento da incineradora LIPOR II, na região do Porto. A recolha de dados realizou-se em Julho de 2002, tendo por base a entrevista directa a 300 indivíduos de ambos os sexos, com mais de 18 anos, residentes nos concelhos do Porto, Maia e Matosinhos.

O Quadro 3 resume as características sociodemográficas da população e da amostra deste estudo. Conforme se observa, os participantes possuem idades compreendidas entre os 18 e os 86 anos, oscilando a média de idades por localidade entre os 45 e os 56 anos. Verifica-se que a maioria dos participantes residem na localidade há bastante tempo, oscilando as médias por localidade entre os 16 e os 43 anos. O nível de instrução da amostra é baixo, tendo sensivelmente metade da mesma frequentado a escola apenas até à $4 .^{\text {a }}$ classe.

Tendo como critério o número de habitantes de cada localidade, constituíram-se três grupos de localidades, que se designaram de: (a) pequena dimensão, que integra as aldeias de Sendal, Crestins, Monte das Pedras, Esposade, Araújo e Custió; (b) média dimensão, que integra as localidades de Senhora da Hora, Maia e Santiago de Custóias; e (c) grande dimensão, que integra as quatro freguesias da cidade do Porto. Relativamente às características sociodemográficas dos grupos constituídos, é de referir a existência de diferenças significativas entre os grupos no que respeita à antiguidade de residência no lugar. Em média, os participantes que residem nas localidades de média dimensão fazem-no há significativamente menos tempo $(F(2,299)=14,13, p<0,000)$ que os residentes nas aldeias e no Porto. Uma vez que na literatura existem indícios de que a antiguidade de residência num lugar se encontra relacionada positivamente com a identidade associada ao lugar (Bonaiuto et al., 1999; Hidalgo \& Hernandéz, 2001), controlou-se posteriormente o efeito desta variável durante a análise de dados. 
Quadro 3: Características sociodemográficas da população e da amostra por localidade

\begin{tabular}{|c|c|c|c|c|c|c|c|c|}
\hline \multirow[b]{2}{*}{ Localidade } & \multirow[b]{2}{*}{ População* } & \multirow[b]{2}{*}{$\mathbf{N}$} & \multirow[b]{2}{*}{$\begin{array}{c}\% \\
\text { Homens }\end{array}$} & \multicolumn{2}{|c|}{ Idade ** } & \multicolumn{2}{|c|}{$\begin{array}{c}\text { Anos de } \\
\text { Residência** }\end{array}$} & \multirow{2}{*}{$\begin{array}{c}\begin{array}{c}\text { Escola- } \\
\text { ridade** }\end{array} \\
\begin{array}{c}\% \text { até } \\
4 .^{\text {a }} \text { classe }\end{array}\end{array}$} \\
\hline & & & & Média & $\begin{array}{l}\text { Desvio } \\
\text { Padrão }\end{array}$ & Média & $\begin{array}{l}\text { Desvio } \\
\text { Padrão }\end{array}$ & \\
\hline Sendal & 205 & 16 & 31,3 & 53,7 & 13,5 & 40,0 & 15,4 & 81,3 \\
\hline Crestins & 569 & 39 & 53,8 & 47,1 & 15,6 & 32,2 & 16,0 & 51,3 \\
\hline $\begin{array}{l}\text { Monte das } \\
\text { Pedras }\end{array}$ & 471 & 13 & 46,2 & 49,5 & 15,9 & 38,8 & 17,5 & 53,8 \\
\hline Esposade & 2357 & 16 & 43,8 & 45,3 & 22,2 & 25,7 & 16,5 & 50,0 \\
\hline Araújo & 1123 & 28 & 66,7 & 51,1 & 17,2 & 41,3 & 17,0 & 55,6 \\
\hline Custió & 1034 & 22 & 40,9 & 48,8 & 17,6 & 33,9 & 20,6 & 50,0 \\
\hline Maia & 16535 & 45 & 53,3 & 46,9 & 16,4 & 21,0 & 11,2 & 55,6 \\
\hline Sr. ${ }^{a}$ da Hora & 19608 & 28 & 57,1 & 52,9 & 16,2 & 37,5 & 18,8 & 53,6 \\
\hline $\begin{array}{l}\text { Santiago de } \\
\text { Custóias }\end{array}$ & 4699 & 21 & 52,4 & 46,8 & 18,6 & 16,2 & 8,3 & 30,0 \\
\hline $\begin{array}{l}\text { Porto- } \\
\text { Paranhos }\end{array}$ & 53022 & 21 & 57,1 & 56,1 & 19,9 & 43,7 & 14,5 & 42,9 \\
\hline $\begin{array}{l}\text { Porto - } \\
\text { Ramalde }\end{array}$ & 36517 & 23 & 52,2 & 50,3 & 19,1 & 29,3 & 14,9 & 43,5 \\
\hline $\begin{array}{l}\text { Porto - } \\
\text { Aldoar }\end{array}$ & 15030 & 16 & 50,0 & 56,3 & 20,3 & 35,6 & 17,6 & 43,5 \\
\hline \multirow[t]{2}{*}{ Porto - Foz } & 12523 & 22 & 45,5 & 51,9 & 20,7 & 42,6 & 22,2 & 45,5 \\
\hline & Total & 300 & 51,0 & 50,0 & 17,9 & 32,4 & 17,9 & 51,5 \\
\hline
\end{tabular}

* Instituto Nacional de Estatística. (1992). Census 91: Resultados Provisórios I, Norte. Lisboa: INE. ** Dados referentes à amostra

\section{Instrumento e Procedimento}

Os dados foram recolhidos utilizando a técnica de entrevista pessoal e directa, conduzida na residência dos participantes, mediante um questionário estruturado que inclui as seguintes medidas:

Conteúdos Identitários.

Introduziu-se um conjunto de 38 itens construídos a partir das categorias obtidas no Estudo 1, solicitando-se aos participantes que, pensando no lugar em que vivem, indicassem o seu grau de acordo relativamente aos mesmos. A resposta aos itens foi dada numa escala de cinco pontos que varia entre 1 ("discorda totalmente") e 5 ("concorda totalmente"). Oito dos itens referem-se a aspectos sociais (e.g., "é onde tenho a minha família"), 
dois itens estão relacionados com características dos habitantes (e.g., "é um local onde vivem pessoas simpáticas"), quatro itens estão relacionados com a riqueza histórico-cultural da localidade (e.g., "é um lugar culturalmente rico"), três itens estão relacionados com o património natural da localidade (e.g., "é um local rodeado de paisagens bonitas"), cinco itens estão relacionados com o ambiente físico e social da localidade (e.g., "é um local muito poluído"), dois itens referem-se a aspectos relacionados com a caracterização sociodemográfica da localidade (e.g., "é um local onde existem problemas sociais"), um item está relacionado com a caracterização económica da localidade (e.g., "é um local onde existem poucas oportunidades de emprégo") e os 13 itens remanescentes prendem-se com infra-estruturas e serviços locais (e.g., "é um local onde existem instalações adequadas para praticar desporto"). De referir que foi introduzido um item relativo às infra-estruturas e serviços de apoio ao idoso, que se considerou pertinente face às características etárias da presente amostra e que não tinha sido apurado no Estudo 1.

Identidade associada ao lugar.

De forma a poder quantificar o grau de identidade associada ao lugar dos participantes, utilizou-se uma medida semelhante à aplicada no Estudo 1 , composta por dois items ("sinto que pertenço a este local", "sinto-me orgulhoso por pertencer a esse local") e que apresentou uma boa consistência interna $(\alpha=0,79)$. A resposta aos itens foi dada numa escala de cinco pontos, que varia entre 1 ("discordo totalmente") e 5 ("concordo totalmente"), sendo utilizado nas análises posteriores um índice composto pela média dos 2 items.

Caracterização Sociodemográfica.

Recolheu-se informação acerca da idade, sexo, nível de instrução completa e anos de residência no lugar.

\section{Resultados}

\section{Estrutura factorial dos conteúdos identitários}

A análise prévia das frequências dos itens determinou a eliminação de sete itens das análises posteriores, em virtude de apresentarem mais de $80 \%$ de concordância e se revelarem, consequentemente, pouco discriminativos. De salientar o facto de cinco dos mesmos dizerem respeito a aspectos sociais, demonstrando um grande consenso relativamente à existência de redes sociais no lugar.

Os restantes 31 itens foram submetidos a uma análise factorial em componentes principais, com rotação varimax, que convergiu numa solução ao fim de seis iterações. Foram eliminados 10 itens por apresentarem pesos factoriais baixos $(<0,40)$ ou por contribuírem para a explicação de dois ou mais factores. 
Quadro 4: Estrutura factorial dos conteúdos identitários (rotação varimax)

\begin{tabular}{|c|c|c|c|c|c|}
\hline & $\begin{array}{c}\text { Factor } 1 \\
\text { Dimensão } \\
\text { Instru- } \\
\text { mental }\end{array}$ & $\begin{array}{c}\text { Factor } 2 \\
\text { Dimensão } \\
\text { Estética }\end{array}$ & $\begin{array}{c}\text { Factor } 3 \\
\text { Dimensão } \\
\text { Histórico- } \\
\text {-Cultural }\end{array}$ & $\begin{array}{c}\text { Factor } 4 \\
\text { Resposta a } \\
\text { Necessida- } \\
\text { des Básicas }\end{array}$ & $\begin{array}{c}\text { Factor } 5 \\
\text { Problemas } \\
\text { Ambientais } \\
\text { e Sociais }\end{array}$ \\
\hline $\begin{array}{l}\text { É um local onde existem instalações } \\
\text { adequadas para praticar desporto }\end{array}$ & 0,86 & & & & \\
\hline $\begin{array}{l}\text {... onde existem jardins e parques } \\
\text { em número suficiente }\end{array}$ & $\mathbf{0 , 8 2}$ & 0,31 & & & \\
\hline $\begin{array}{l}\text {... com jardins de infância, escolas e } \\
\text { outras instituições de ensino em } \\
\text { número suficiente }\end{array}$ & $\mathbf{0 , 8 1}$ & & & & \\
\hline $\begin{array}{l}\text {... onde existem cuidados e serviços } \\
\text { médicos adequados }\end{array}$ & $\mathbf{0 , 7 7}$ & & & & \\
\hline $\begin{array}{l}\text {... onde existem actividades e } \\
\text { ocupações para o fim de semana }\end{array}$ & $\mathbf{0 , 7 7}$ & 0,37 & & & \\
\hline $\begin{array}{l}\text {... onde se realizam espectáculos } \\
\text { com frequência }\end{array}$ & 0,76 & 0,40 & & & \\
\hline $\begin{array}{l}\text {... onde existem poucas } \\
\text { oportunidades de emprego }\end{array}$ & $-0,61$ & & & & \\
\hline É um local bonito & & $\mathbf{0 , 8 3}$ & & & \\
\hline ... rodeado de paisagens bonitas & & $\mathbf{0 , 7 7}$ & 0,40 & & \\
\hline $\begin{array}{l}\text {... onde nos sentimos perto da } \\
\text { natureza }\end{array}$ & & 0,74 & 0,42 & & \\
\hline ... agradável para viver & & 0,69 & & 0,32 & \\
\hline $\begin{array}{l}\text {... onde ainda se mantêm vivas } \\
\text { tradições antigas }\end{array}$ & & & $\mathbf{0 , 8 1}$ & & \\
\hline ... onde a população é unida & & & $\mathbf{0 , 7 0}$ & 0,37 & \\
\hline $\begin{array}{l}\text {... com um passado histórico } \\
\text { interessante }\end{array}$ & 0,39 & & 0,69 & & \\
\hline $\begin{array}{l}\text {... onde tenho as minhas amizades, } \\
\text { os meus amigos }\end{array}$ & & & & $\mathbf{0 , 8 2}$ & \\
\hline $\begin{array}{l}\text {... onde existem os serviços } \\
\text { essenciais para o dia-a-dia }\end{array}$ & & 0,31 & & 0,71 & \\
\hline $\begin{array}{l}\text {... onde não temos privacidade } \\
\text { porque as pessoas se intrometem } \\
\text { na vida dos outros }\end{array}$ & & & & $-0,66$ & \\
\hline ... onde existem problemas sociais & & & & & $\mathbf{0 , 8 2}$ \\
\hline É um local com muito trânsito & & & & & $\mathbf{0 , 7 0}$ \\
\hline É um local inseguro & & & & $-0,35$ & 0,56 \\
\hline Alfa & 0,86 & 0,89 & 0,77 & 0,64 & 0,60 \\
\hline \% Variância explicada & $25,04 \%$ & $15,24 \%$ & $11,15 \%$ & $10,20 \%$ & $08,99 \%$ \\
\hline \% Variância explicada total: & $70,62 \%$ & & & & \\
\hline
\end{tabular}


O Quadro 4 apresenta os resultados finais. Foram extraídos cinco factores que explicam no seu conjunto $70,62 \%$ da variação existente. $\mathrm{O}$ factor 1, designado de Dimensão Instrumental, inclui oito itens relativos às infra-estruturas e serviços locais, ofertas culturais e de lazer e oportunidades de emprego e explica $25,04 \%$ da variação. O factor 2 , designado de Dimensão Estética, é composto por quatro itens relativos ao património natural e à avaliação positiva da localidade e explica $15,24 \%$ da variação. O factor 3, designado de Dimensão Histórico-Cultural, agrega três itens relativos ao sentido de comunidade e riqueza histórico-cultural da localidade, explicando $11,15 \%$ da variação. $\mathrm{O}$ factor 4 , designado de Resposta a Necessidades Básicas, agrega três itens relativos às redes sociais, privacidade e existência de serviços essenciais, explicando $10,20 \%$ da variação. Por fim, o factor 5, designado de Problemas Ambientais e Sociais, reúne três itens relacionados com problemas ambientais e sociais e explica 8,99\% da variação. Os factores apresentam os seguintes valores de consistência interna (alfa de Cronbach): 0,86, 0,89, 0,77, 0,64 e 0,60, respectivamente.

\section{Identidade associada ao lugar: diferenças em função da dimen- são da localidade}

No que se refere ao grau de identificação, constata-se que, de uma forma geral, os participantes se apresentam bastante identificados com as suas localidades $(M=4,23 ; D P=0,76)$. Existem, todavia, diferenças em função da dimensão da localidade onde residem $(F(2,300)=3,24$, $p<0,05)$. Assim, embora todos se identifiquem bastante com os lugares onde residem, os participantes que vivem em localidades pequenas e médias identificam-se ainda mais com a sua localidade do que os que vivem no Porto ( $M=4,31$ e $M=4,25$ vs. $M=4,09$, respectivamente).

Com vista à análise da relação entre o grau de identidade e as restantes variáveis em estudo, constituíram-se, com base na média da amostra, dois grupos que se designaram de baixa $(45,7 \%)$ e alta identidade associada ao lugar $(54,3 \%)$.

\section{Conteúdos identitários: diferenças em função do grau de identi- dade associada ao lugar}

Existem diferenças significativas nos níveis de concordância com os conteúdos em função do grau de identidade reportado (Quadro 5). Assim, os indivíduos mais identificados mostram-se mais concordantes relativamente às dimensões Instrumental $(F(1,273)=20,94, p<0,000)$, Estética 
$(F(1,273)=50,31, p<0,000)$, Histórico-Cultural $(F(1,273)=25,39, p<0,000)$ e Resposta a Necessidades Básicas $(F(1,273)=67,01, p<0,000)$ do que os menos identificados. Relativamente à dimensão Problemas Ambientais e Sociais, que reúne características marcadamente negativas do lugar, são os participantes menos identificados que revelam um nível mais elevado de concordância $(F(1,273)=11,95, p<0,001)$. Estes resultados sugerem que os participantes mais identificados com a localidade em que residem percepcionam a mesma de forma globalmente mais positiva do que os menos identificados, maximizando as características positivas e minimizando as características negativas. Os participantes menos identificados apresentam o comportamento inverso.

Quadro 5: Diferenças nos conteúdos identitários em função do grau de identidade associada ao lugar

\begin{tabular}{lcccccc}
\hline & \multicolumn{2}{c}{ Baixa Identidade } & \multicolumn{2}{c}{ Alta Identidade } & \multicolumn{2}{c}{ Total da Amostra } \\
\cline { 2 - 7 } & Média & DP & Média & DP & Média & DP \\
Conteúdos & 2,88 & 0,78 & $3,30^{*}$ & 0,80 & 3,08 & 0,81 \\
\hline Dimensão Instrumental & 3,47 & 0,93 & $4,19^{*}$ & 0,70 & 3,80 & 0,90 \\
Dimensão Estética & 3,42 & 0,82 & $3,92^{*}$ & 0,72 & 3,65 & 0,78 \\
Dimensão Histórico-Cultural & 3,51 & 0,71 & $4,20^{*}$ & 0,70 & 3,82 & 0,83 \\
Resposta a Necessidades Básicas & 3,23 & 0,78 & $2,89^{* *}$ & 0,84 & 3,08 & 0,71 \\
Problemas Ambientais e Sociais & 3,23 & & & & & \\
\hline
\end{tabular}

$* p<0,000 ; * * p<0,05$

\section{Conteúdos Identitários: diferenças em função da dimensão da localidade}

Existem igualmente diferenças significativas na forma como os participantes utilizam os conteúdos para avaliar localidades de diferente dimensão, conforme se observa no Quadro 6.

Relativamente às dimensões Instrumental e Estética, verifica-se que, em termos gerais, os participantes consideram que as localidades onde vivem oferecem genericamente razoáveis oportunidades de emprego e boas infra-estruturas e serviços locais $(M=3,08 ; D P=0,81)$ e são locais bonitos e agradáveis para se viver $(M=3,80 ; D P=0,90)$. Não obstante, os participantes residentes nas localidades de média dimensão atribuem, por um lado, uma ainda maior instrumentalidade à sua localidade, mostrando-se mais satisfeitos com as oportunidades de emprego e com as várias infra-estruturas e serviços disponíveis e, por outro, percepcionam as suas loca- 
lidades como mais belas e agradáveis do que os restantes participantes $(F(2,272)=62,21, p<0,000$; e $F(2,272)=8,18, p<0,000$, respectivamente).

No que respeita às dimensões Histórico-Cultural e Resposta a Necessidades Básicas, observa-se que, na globalidade, os participantes consideram igualmente que, nas suas terras, a população é unida e preserva a riqueza das tradições e do passado histórico $(M=3,65 ; D P=0,81)$ e que são locais onde têm os seus amigos, privacidade e os serviços essenciais ao dia-a-dia $(M=3,82 ; D P=0,78)$. Ainda assim, verificam-se diferenças significativas em função da dimensão da localidade, com os participantes residentes nas aldeias e nas localidades de média dimensão a fazerem uma avaliação mais positiva das suas localidades nestas dimensões do que os participantes residentes na cidade do Porto $(F(2,272)=7,69, p<0,001 \mathrm{e}$ $F(2,272)=24,47, p<0,000$, respectivamente)

Quanto à dimensão Problemas Ambientais e Sociais, verifica-se que, na globalidade os participantes consideram que existe insegurança, tráfego elevado e problemas sociais nas localidades onde vivem $(M=3,08$; $D P=0,83)$. Todavia, a percepção de problemas ambientais e sociais parece aumentar com a dimensão da localidade, uma vez que todos os grupos apresentam diferenças significativas entre si nesta dimensão $(F(2,272)=$ $15,16, p<0,000)$. O resultado da correlação de Pearson entre as variáveis comprova a existência de uma associação positiva entre as mesmas $(\mathrm{r}=0,32, \mathrm{p}<0,01)$. Os residentes nas aldeias são os que percepcionam a existência de menos problemas a este nível, seguidos dos residentes nas localidades médias e, finalmente, dos residentes do Porto, que são os que percepcionam a existência de mais problemas ambientais e sociais na sua zona de residência.

Quadro 6: Diferenças nos conteúdos identitários em função da dimensão da localidade

\begin{tabular}{|c|c|c|c|c|c|c|c|c|}
\hline \multirow[b]{3}{*}{ Conteúdos } & \multicolumn{6}{|c|}{ Dimensão da Localidade } & \multirow{2}{*}{\multicolumn{2}{|c|}{$\begin{array}{l}\text { Total da } \\
\text { Amostra }\end{array}$}} \\
\hline & \multicolumn{2}{|c|}{ Pequenas } & \multicolumn{2}{|c|}{ Médias } & \multicolumn{2}{|c|}{ Grandes } & & \\
\hline & Média & DP & Média & DP & Média & DP & Média & DP \\
\hline Dimensão Instrumental & $2,76 \mathrm{a}$ & 0,75 & $3,76 \mathrm{~b}$ & 0,52 & $2.79 a^{*}$ & 0,69 & 3,08 & 0,81 \\
\hline Dimensão Estética & $3,74 \mathrm{a}$ & 0,96 & $4,10 \mathrm{~b}$ & 0,66 & $3,55 a^{*}$ & 0,97 & 3,80 & 0,90 \\
\hline Dimensão Histórico-Cultural & $3,70 \mathrm{a}$ & 0,85 & $3,84 \mathrm{a}$ & 0,54 & $3,36 b^{* *}$ & 0,93 & 3,65 & 0,81 \\
\hline Resposta a Necessidades Básicas & $4,02 \mathrm{a}$ & 0,74 & $4,00 \mathrm{a}$ & 0,75 & $3,32 b^{*}$ & 0,66 & 3,82 & 0,78 \\
\hline Problemas Ambientais e Sociais & $2,81 \mathrm{a}$ & 0,86 & $3,11 \mathrm{~b}$ & 0,73 & $3,45 c^{*}$ & 0,73 & 3,08 & 0,83 \\
\hline
\end{tabular}

$* p<0,000 ; * * p<0,001$ 


\section{Conteúdos identitários: efeito de interacção entre identidade as-} sociada ao lugar e dimensão da localidade

A análise dos efeitos de interacção entre identidade associada ao lugar e dimensão da localidade sobre os conteúdos identitários foi realizada mediante o cálculo de análises univariadas de variância para cada uma das dimensões identificadas. Os resultados revelam apenas um efeito de interacção significativo na dimensão Resposta a Necessidades Básicas $(F(2,272)=2,99, p<.05)$. A Figura 3 permite visualizar este resultado e mostra que, no Porto, é menor a diferenciação das respostas dos indivíduos com identidade baixa e alta do que nas localidade de menor dimensão.

Figura 3: Efeito da identidade associada ao lugar e da dimensão da localidade sobre a Dimensão Resposta a Necessidades Básicas

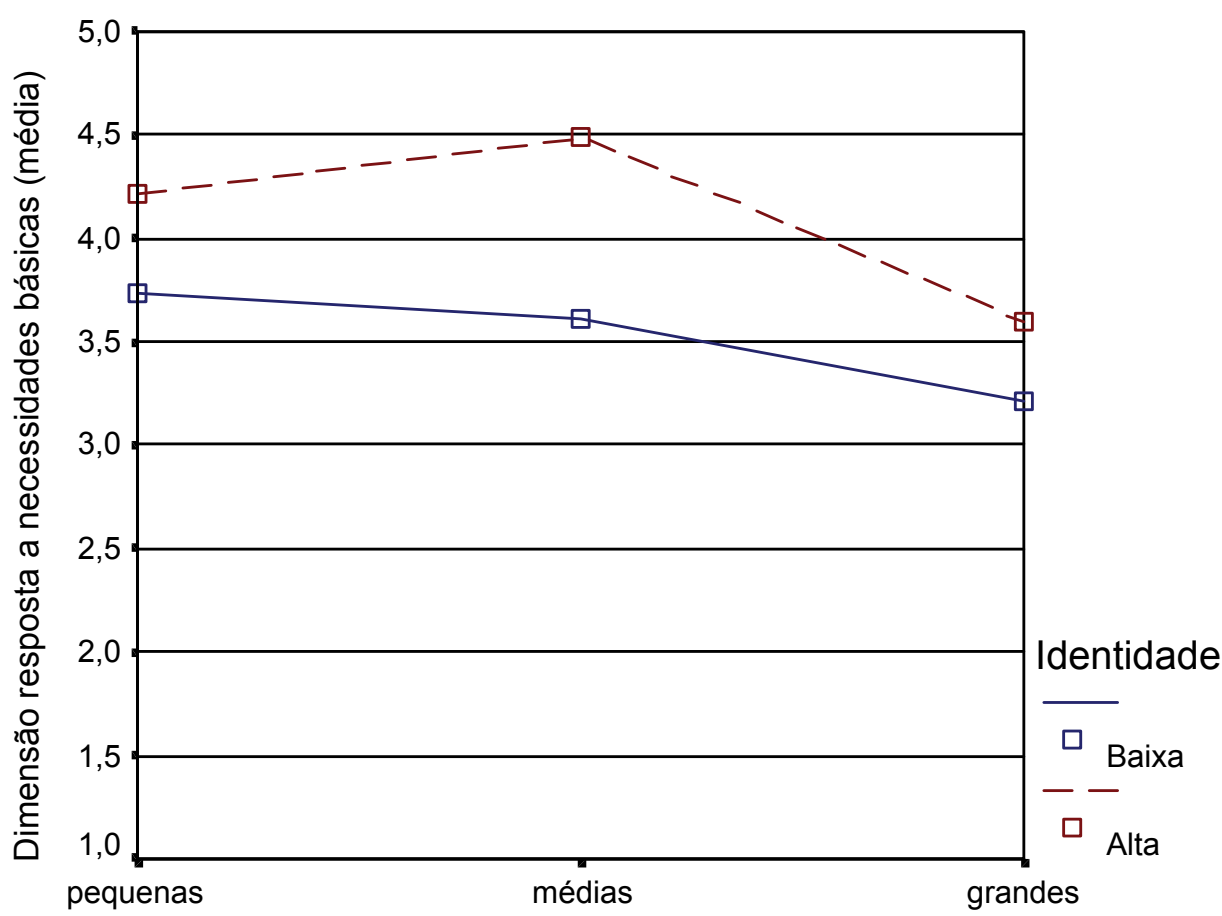

Dimensão da localidade 
De facto, a comparação dos níveis médios de concordância com a dimensão Resposta a Necessidades Básicas apresentados pelos participantes com baixa identidade revela que existe uma diferença significativa entre os que habitam em localidades pequenas $(M=3,73 ; D P=0,77)$ e médias $(M=3,61 ; D P=0,65)$ e os que habitam no Porto $(M=3,22 ; D P=0,71)$ $(F(2,147)=8,20, p<0,000)$, ocorrendo o mesmo entre os que apresentam alta identidade (pequenas: $M=4,22 ; \quad D P=0,65$; médias: $M=4,49$; $D P=0,58$; Porto: $M=3,60 ; D P=0,73 ; \quad F(2,124)=12,81, p<0,000)$. Assim, os participantes que habitam no Porto, independentemente do grau de identidade com a cidade, consideram que a mesma satisfaz menos as suas necessidades básicas do que os participantes que vivem nas localidades de pequena e média dimensão.

Figura 4: Efeito da identidade associada ao lugar e da dimensão da localidade sobre a Dimensão Estética

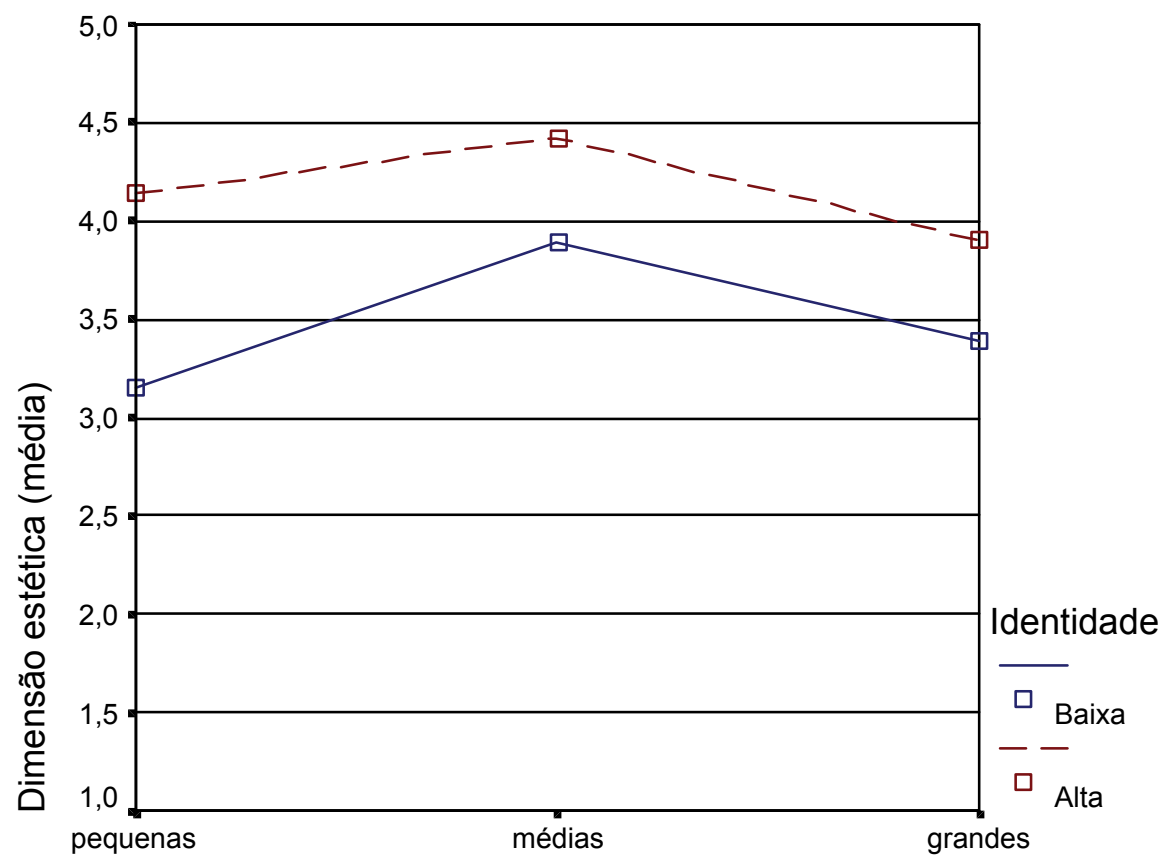

Dimensão da localidade 
Os resultados revelam ainda a existência de um efeito de interacção marginalmente significativo a 0,07 na dimensão Estética $(F(2,272)=2,67)$ que vai no sentido do anterior, uma vez que salienta o facto de a diferenciação das respostas por níveis de identidade ser maior no caso das localidades de menor dimensão do que no Porto (Figura 4). Assim, a comparação dos níveis médios de concordância com esta dimensão apresentados pelos participantes com baixa identificação revelam uma diferença significativa entre os que vivem nas localidades de média dimensão $(M=3,87 ; D P=0,55)$ e os que vivem nas aldeias $(M=3,15$; $D P=0,97)$ e no Porto $(M=3,39 ; D P=1,03)(F(2,174)=8,07, p<0,000)$, sendo que os primeiros consideram a sua localidade como mais bonita que os restantes. Entre os participantes que reportam alta identidade, o efeito é apenas marginal $(F(2,124)=2,92, p<0,06)$, mas vai no mesmo sentido (médias: $M=4,39 ; D P=0,68$; pequenas: $M=4,16 ; D P=0,71$; Porto: $M=3,95 ; D P=0,65)$. No seu conjunto, estes resultados sugerem que, independentemente do grau de identidade manifestado, os participantes que vivem nas localidades de média dimensão consideram os lugares onde vivem como mais bonitos e agradáveis do que os restantes participantes.

\section{Discussão}

O presente estudo visou analisar a estrutura factorial dos conteúdos subjacentes à identidade associada ao lugar, bem como estudar a relação entre estes, o grau de identificação com o lugar e a dimensão da localidade que promove a identificação.

Os resultados demonstram que os conteúdos identitários têm uma estrutura complexa, agrupando-se em cinco dimensões principais. Verifica-se que estas dimensões traduzem ideias presentes na proposta teórica de Breakwell (1986, 1992, 1993, 2001). Neste sentido, as dimensões Instrumental e Problemas Ambientais e Sociais reúnem um conjunto de itens relativo a questões de auto-eficácia, enquanto que as dimensões Estética e a Histórico-Cultural reúnem itens que parecem relacionar-se com as funções de distintividade, auto-estima e também continuidade.

A forma como estes conteúdos são utilizados pelos habitantes para caracterizar as suas terras é influenciada, quer pela sua identidade com o lugar, quer pela dimensão do mesmo. No que respeita ao grau de identidade, os resultados sugerem que os indivíduos mais identificados percepcionam de forma globalmente mais positiva os lugares onde vivem do que os menos identificados, maximizando as características positivas e minimizando as negativas, apresentando um enviesamento ou favoritismo pelo endogrupo (Tajfel, 1978, 1981; Tajfel \& Turner, 1979; Turner, 1987). Este 
facto, por seu turno, apoia a ideia de que o ambiente residencial é importante para a identidade e auto-estima dos indivíduos.

As características das localidades de diferente dimensão estão associadas a uma utilização diferenciada dos conteúdos identitários, sugerindo que a forma como os indivíduos se relacionam com o seu ambiente e constroem a sua identidade é influenciada não só pelas características que lhe são subjectiva ou socialmente atribuídas, mas também pelas características objectivas dos próprios lugares.

\section{Conclusão geral}

A investigação aqui reportada pretendeu superar a negligência a que tem sido votado o estudo dos conteúdos da identidade associada ao lugar, assumindo para tal uma perspectiva essencialmente qualitativa. Procurou-se, num primeiro estudo, identificar as dimensões subjacentes à identidade associada ao lugar, para posteriormente analisar a sua estrutura factorial através de um segundo estudo. Em ambas as pesquisas, procedeu-se à análise dos conteúdos identitários atendendo ao grau de identidade reportado pelos participantes e à dimensão das localidades onde estes vivem.

Entre as possíveis conclusões a retirar, refira-se a complexidade e multiplicidade dos conteúdos subjacentes à identificação com os lugares, cujos resultados sugerem estruturar-se segundo cinco dimensões com correspondência clara à proposta de Breakwell (1986, 1992, 1993, 2001). A existência de similaridades entre os conteúdos identificados no presente estudo, os de Bonaiuto e colaboradores (1999) e os de Gustafson (2001) apontam para a existência de constância nas características e dimensões com base nas quais as pessoas avaliam e edificam a sua identidade associada ao lugar.

Refira-se também a existência de visões distintas de aldeias, vilas e cidades, que correspondem genericamente às popularizadas pelo senso comum, assentam na atribuição de características específicas a cada localidade e atestam da importância que a própria dimensão da localidade e características físicas podem exercer sobre o processo identificativo.

Outra conclusão importante prende-se com a relação existente entre os conteúdos identitários e o próprio grau de identidade com o lugar. Os resultados permitem concluir que os residentes mais identificados com os lugares apresentam uma visão mais positiva dos mesmos, considerando-os mais funcionais, bonitos, ricos em património histórico e cultural, capazes de satisfazer necessidades básicas e com menos problemas ambientais, do que os residentes menos identificados. 
Muito embora os resultados obtidos com este projecto ajudem a elucidar a relação que se estabelece entre identidade e ambiente, persiste a necessidade de desenvolver mais pesquisa sobre esta problemática. A existência de condicionalismos ao nível das amostras utilizadas aconselha prudência na generalização dos resultados. Por exemplo, a predominância de jovens (idade média de 22 anos) do sexo feminino (84\%), o que corresponde ao perfil do estudante universitário de ciências sociais, na composição da amostra do Estudo 1 pode ter influenciado a natureza dos conteúdos identificados. De forma a salvaguardar as ilações a retirar destes estudos, pretende-se, num alargamento futuro deste projecto, proceder a replicações junto de amostras mais heterogéneas e tanto quanto possível representativas da população portuguesa. Mais, a literatura indica que a identidade associada ao lugar não é apenas um produto das características do lugar, mas também das características das pessoas e da sua relação com o meio (Cuba \& Hummon, 1993), pelo que a generalização directa de resultados de uns contextos para outros é sempre desaconselhada. No entanto, pensamos que este trabalho permite avançar numa direcção importante, que é a da definição das dimensões nas quais se dá a diferenciação entre as localidades. Neste sentido, a escala de conteúdo construída parece-nos permitir abrir novos domínios de pesquisa nesta área.

\section{Referências}

Almeida, I., \& Castro, P. (2002). Realojamento: Satisfação residencial e identidade local. Comunicação apresentada no I Colóquio Psicologia, Espaço e Ambiente, Universidade de Évora.

Aragonés, J., Corraliza, J., Cortês, B., \& Amérigo, M. (1992). Perception of territory and social identity. In A. Mazis \& C. Karaletsou (Orgs.), Socio-environmental metamorphoses. Salónica: University of Tessaloniki.

Baltazar, A. (2002). Identidade associada ao lugar: Conteúdos identitários e percepção de qualidade ambiental. Tese de mestrado não publicada. Lisboa: ISCTE.

Bonaiuto, M., \& Bonnes, M. (1996.) Multiplace analysis of the urban environment: A comparison between a large and a small italian city. Environment and Behavior, 28, 699-747.

Bonaiuto, M., Breakwell, G., \& Cano, I. (1996). Identity processes and environmental threat: The effects of nationalism and local identity upon perception of beach pollution. Journal of Community and Applied Social Psychology, 6, 157-175 .

Bonaiuto, M., Aiello, A., Perugini, M., Bonnes, M., \& Ercolani, A. (1999). Multidimensional perception of residential environment quality and neighborhood attachment in the urban environment. Journal of Environmental Psychology, $19,331-352$. 
Breakwell, G. (1986). Coping with threatened identity. London: Methuen.

Breakwell, G. (1992). Processes of self-evaluation: Efficacy and estrangement. In G. Breakwell (Org.), Social psychology of identity and the self-concept. Surrey: Surrey University Press.

Breakwell, G. (1993). Integrating paradigms: Methodological implications. In G. Breakwell \& D. Canter (Orgs.), Empirical approaches to social representations. Oxford: Clarendon Press.

Breakwell, G. (2001). Social representations constraints upon identity processes. In G. Philogene \& K. Deaux (Orgs.), Representations of the social: Bridging theoretical traditions (pp. 271-284). Londres: Blackwell Publishers.

Chawla, L. (1992). Childhood place attachments. In I. Altman \& S. Low (Orgs.), Place attachment. Nova Iorque: Plenum Press.

Cortês, B., \& Aragonés, J. (1991). Identidad social y territorio. Analisis cualitativo del discurso sobre los espacios comarcales de la comunidad de Madrid. In R. Castro (Org.), Psicologia ambiental: Intervención y evaluación del entorno. Sevilha: Arquetipo.

Cuba, L., \& Hummon, D. (1993). A place to call home: Identification with dwelling, community and region. Sociological Quartely, 34, 111-131.

Devine-Wright, P., \& Lyons, E. (1997). Remembering pasts and representing places: The construction of national identities in Ireland. Journal of Environmental Psychology, 17, 33-45.

Dixon, J., \& Durrheim, K. (2000). Displacing place identity: A discursive approach to locating self and other. British Journal of Social Psychology, 39, 27-44.

Feldman, R. (1990). Settlement identity: Psychological bonds with home places in a mobile society. Environment and Behavior, 22, 183-229.

Fried, M. (1982). Residential attachment: Sources of residential and community satisfaction. Journal of Social Issues, 38, 107-119.

Fried, M. (2000). Continuities and discontinuities of place. Journal of Environmental Psychology, 20, 193-205.

Giuliani, M., \& Feldman, R. (1993). Place attachment in a developmental and cultural context. Journal of Environmental Psychology, 13, 267-274.

Gustafson, P. (2001). Meaning of place: Everyday experience and theoretical conceptualizations. Journal of Environmental Psychology, 21, 5-16.

Hidalgo, M., \& Hernandéz, B. (2001). Place attachment: Conceptual and empirical questions. Journal of Environmental Psychology, 21, 273-281.

Hummon, D. (1992). Community attachment: Local sentiment and sense of place. In I. Altman \& S. Low (Orgs.), Place attachment (pp. 253-278). Nova Iorque: Plenum Press.

Jorgensen, B., \& Stedman, R. (2001). Sense of place as an attitude: Lakeshore owners attitudes toward their properties. Journal of Environmental Psychology, 21, 233-248.

Korpela, K. (1989). Place identity as a product of environmental self regulation. Journal of Environmental Psychology, 9, 241-256. 
Krupat, E. (1983). A place for place identity. Journal of Environmental Psychology, $3,343-344$.

Krupat, E. (1985). People in cities: The urban environment and its effects. Cambridge: Cambrigde University Press.

Lalli, M. (1988). Urban related identity. In D. Canter, J. Jesuino, L. Soczka, \& G. Stephenson (Orgs.), Environmental social psychology (pp. 303-311) Londres: Kluwer Academic Press.

Lalli, M. (1992). Urban related identity: Theory, measurement and empirical findings. Journal of Environmental Psychology, 12, 285-303.

Lima, M. L. (1998). Factores sociais na percepção de riscos. Psicologia, 12, 11-28.

Lima, M. L. (1999). Percepção de riscos ambientais: Uma abordagem psicossociológica. Comunicação apresentada no Ciclo de Conferências - Temas e Debates em Psicologia Social e Organizacional. Lisboa: ISCTE.

Lima, M. L. (2002). As marcas dos lugares nas pessoas: Identidade, apropriação e relações de vizinhança. In L. G. Brito (Org.), Gestão urbana: Passado, presente, futuro. Lisboa: Parque Expo.

Lima, M. L., \& Palma-Oliveira, J. (2001). Relatório da monitorização psicossocial da Lipor II: Campanha de Verão de 2001. Lisboa: Centro de Investigação e de Intervenção Social.

Low, S., \& Altman, I. (1992). Place attachment: A conceptual inquiry. In I. Altman \& S. M. Low (Orgs.), Place attachment (pp. 1-12). Nova Iorque: Plenun Press.

Proshansky, H., Fabian, A., \& Kaminoff, R. (1983). Place identity: Physical world socialization of the self. Journal of Environmental Psychology, 3, 57-83.

Proshansky, M. (1978). The city and the self identity. Environment and Behavior, 10, 147-169.

Relph, E. (1976). Place and placelessness. Londres: Pion.

Riley, R. (1992). Attachment to ordinary landscape. In I. Altman \& S. Low (Orgs.), Place attachment. Nova Iorque: Plenum Press.

Robson, C. (1993). Real world research: A source for social scientists and practioner researchers. Oxford: Blackwell.

Rowles, G. (1983). Place and personal identity in old age: Observation from Appalachia. Journal of Environmental Psychology, 3, 299-313.

Speller, G., Lyons, E., \& Twigger-Ross, C. (1996). The imposed relocation of Arkwright: Self-evaluation processes and representation of social chage in a mining community. Comunicação apresentada na EAESP Conference, Áustria.

Speller, G., Lyons, E., \& Twigger-Ross, C. (2002). A community in transition: The relationship between spatial change and identity processes. Social Psychological Review, 4, 39-58.

Stedman, R. (2002). Toward a social psychology of place: Predicting Behavior from place-based cognitions, attitude and identity. Environment and Behavior, 34, 561-581.

Stokols, D., \& Sumaker, S. (1981). People in places: A transactional view of settings. In J. Harvey (Org.), Cognition, social behavior and environment. Nova Jérsia: Erlbaum. 
Tajfel, H. (1978). Differentiation between social groups. Londres: Academic Press.

Tajfel, H. (1981). Human groups and social categories. Cambridge: Cambridge Academic Press.

Tajfel, H., \& Turner, J. (1979). An integrative theory of intergroup conflict. In W. Austin \& S. Worchel (Orgs.), The social psychology of intergroup behavior, California: Brooks Cole.

Turner, J. (1987). Self categorization theory. In J. Turner, M. Hogg, P. Oakes, S. Reicher, \& M. Wetherell (Orgs.), Rediscovering the social group: A self-categorization theory. Oxford: Basil Blackwell.

Twigger-Ross, C., \& Uzzel, L. (1996). Place and identity processes. Journal of Environmental Psychology, 16, 205-220.

Valera, S., \& Pol, E. (1994). El concepto de identidad social urbana: Una aproximación entre la Psicología Social y la Psicología Ambiental. Anuario de Psicología, 62, 5-24. 